\title{
LOS ACTOS DE LOS GOBIERNOS DEPARTAMENTALES Y SU CONTROL POR LOS MECANISMOS DE GOBIERNO DIRECTO
}

\begin{abstract}
RESUMEN. A nivel de los gobiernos departamentales, la Constitución uruguaya prevé dos mecanismos de participación directa de las personas, el referéndum y la iniciativa popular. La jurisprudencia de la Corte Electoral hasta 2013 había negado la existencia de dichos institutos so pretexto de que debían ser reglamentados por el legislador. La actual jurisprudencia de dicho organismo ha sido consagrar la existencia de ambos institutos, aunque con serias limitaciones que violan, a juicio del autor, el texto constitucional, que se analizan en el presente artículo.
\end{abstract}

Jean-PaulTealdi

PALABRAS CLAVES. Uruguay. Gobierno Departamental. Corte Electoral. Referéndum. Iniciativa popular.

ABSTRACT. At Local Governments' level, Uruguay's Constitution states two mechanisms for direct participation, namely: referendum and popular initiative. Until 2013, the Electoral Board's case law had denied the existence of such institutes, arguing that they required to be regulated by the lawmaker. Current case law of such Board, however, enshrines the existence of both institutes, although with serious limitations that, to the author's view, violate the constitutional text, and that are analyzed throughout this paper.

KEY WORDS. Uruguay. Local Government. Electoral Board. Referendum. Popular Initiative.

\section{INTRODUCCIÓN.}

En el Uruguay la Constitución de 1934 creó el instituto del referéndum a nivel departamental, y la iniciativa a nivel local, y el legislador en 1935 cumplió el mandato constitucional pero lo amplió y creó el instituto de la iniciativa legislativa departamental.

Procurador. Asistente de Derecho Constitucional (Grado 2), Facultad de Derecho, UDELAR. Ayudante del Instituto de Derecho Constitucional de la Facultad de Derecho, UDELAR (2018-2019). Correo electrónico: jampiuru@gmail.com 
La Constitución de 1952 estableció que la Ley creada por mayoría absoluta debía reglamentar el recurso de referéndum contra los decretos de los gobiernos departamentales, y que la ley podía instituir y reglamentar el derecho de iniciativa legislativa departamental.

Al amparo de lo dispuesto en la Constitución uruguaya y la ley mencionada, se accionaron diversos procedimientos tendientes a interponer recursos de referéndum contra decretos de diversos gobiernos departamentales, así como ejercer el derecho de iniciativa legislativa en materia departamental. El órgano encargado de proceder al análisis de la pertinencia o no de ambos institutos es la Corte Electoral, quien tiene la competencia consagrada constitucionalmente. La jurisprudencia en esta materia ha establecido la inexistencia de ambos institutos, debiendo el legislador proceder a dictar las leyes reglamentarias que prevén las normas constitucionales.

Sin embargo, a partir de 2013, 2014 la Corte Electoral ha establecido en su reciente jurisprudencia la existencia de ambos institutos, y en 2017 restringió el ejercicio del referéndum contra decretos que establecen tributos.

Atento a la trascendencia que dicha jurisprudencia tiene respecto del ejercicio directo de la soberanía por parte de la Nación, nos disponemos al análisis de dichos fallos a la luz del Estado constitucional de derecho y de los institutos democracia directa, y establecemos nuestra posición respecto de los fundamentos y conclusiones que ha establecido la Corte Electoral.

\section{ESTADO DE DERECHO Y LOS INSTITUTOS DE GOBIERNO DIRECTO.}

\subsection{El Estado de Derecho.}

\subsubsection{Orígenes.}

El Estado de Derecho, en sus orígenes, aparece confundido con el Estado Liberal, condicionado por una realidad social y económica, e íntimamente vinculada a la ideología liberal.

Maurice DUVERGER señala que las instituciones políticas se desarrollan a partir y con base en una ideología preexistente, que se manifiesta en el liberalismo político, establecido claramente en el artículo primero de la Declaración de Derechos del Hombre y del Ciudadano de 1789 al expresar que "Los hombres nacen y permanecen libres e iguales en derechos", la cual debe ser situada dentro de la realidad económica y social en que se desarrolló la revolución burguesa. Se buscaba limitar los poderes de los gobernantes, de manera tal que el Estado no interfiriera con la realidad. En segundo término la ideología liberal en lo económico que se manifestaba en la libertad de empresa, respeto a la propiedad privada y libertad de comercio.

En su formulación jurídica nace en medio de dos planteos fundamentales: a). el principio inglés del "rule of law", que implica la primacía total de la ley, consagrándose la soberanía del parlamento inglés, recogido por la doctrina del liberalismo político y jurídico, era ya desde tiempo atrás un principio consuetudinario constitucional plenamente vigente en el siglo XVII. b). Los planteos del jusnaturalismo racionalizado, representada entre otros por GROCIO y KANT, así como la doctrina de la separación de poderes, cuyos exponentes más conocidos son LOCKE, HOBBES y MONTESQUIEU ${ }^{1}$.

1 CORREA FREITAS, Ruben. Derecho Constitucional Contemporáneo, Tomo I, F.C.U., Cuarta Edición, Uruguay. 2013, p. 93. 
En la doctrina alemana proclama la soberanía del Derecho, ante la imposibilidad de reconocer como en Inglaterra la primacía del Parlamento, acuñándose la expresión Estado de Derecho se le otorga a VONMOHL, en una obra publicada en 1832, cuyo título es "Ciencia de la Policía según los principios del Estado de Derecho", el que destacó tres períodos históricos del Estado: a) El Estado patrimonial, en el que el gobierno absoluto administra el Estado como si fuese un patrimonio personal del soberano; b) El Estado de Policía, que es el gobierno absoluto del Estado dirigido con fines de bien público, pero con normas arbitrarias y reglamentarias; c) El Estado de Derecho, es el gobierno regido por la ley y cuyo fin es al mismo tiempo la justicia y el bien público ${ }^{2}$.

\subsubsection{Caracteres.}

Sobre el significado y alcance del Estado de Derecho, afirma FERNANDEZ SEGADO que "desde su formulación inicial, la cláusula del 'Estado de Derecho' ha encerrado un conjunto de convicciones y creencias, esto es, un orden axiológico determinado. El Estado de Derecho fue ante todo un Estado garante de la libertad y seguridad individuales" .

En la doctrina nacional, REAL define al Estado de Derecho como "aquel que en sus relaciones con sus súbditos y para garantía de los derechos de éstos, se somete el mismo a un régimen de derecho y está sujeto en su acción a reglas que, primero, determinan los derechos que se reservan los ciudadanos (los habitantes en general) y segundo, fijan las vías y medios por los cuales las autoridades públicas pueden lograr los fines del Estado" .

Por su parte, JIMENEZ DE ARECHAGA que prefería distinguir entre los "gobiernos de opinión" y los "gobiernos de fuerza", expresa que las características del Estado de Derecho se pueden sintetizar en "la idea de que el Estado es limitado en cuanto a sus fines; la idea de que el Estado está limitado por el derecho; la idea de que el derecho está limitado por la razón; la idea de que el gobierno es limitado, en cuanto lo es el Estado mismo; es limitado, en cuanto lo es el derecho que él produce y es limitado también en cuanto su actuación está subordinada al derecho"5.

DE VERGOTTINI señaló que el Estado de Derecho se propagó por Europa y se consolidó y articuló en una serie de postulados irrenunciables que eran: a). supremacía de la ley parlamentaria en cuanto expresión, mediante el principio representativo, de la soberanía popular. El término ley, si bien definido de modo formalista se entendió en sentido amplio, y por ende, comprendía la ley-base del Estado, su Constitución; b). un sistema jerárquico de normas jurídicas ordenadas de acuerdo a diversos grados, con capacidad diferenciada de intervención en las relaciones sociales; c). separación de poderes públicos dotados de esferas de competencias propias, como garantía de libertad; d). reconocimiento expreso y sistema de garantías de la libertad previstas por la Constitución, y e). principio de legalidad de la acción de la administración y sistemas de recursos contra la acción administrativa de carácter ilegítimo ${ }^{6}$.

2 CORREA FREITAS, Ruben. Ob. Cit., p. 93.

CORREA FREITAS, Ruben. Ob. Cit., p. 94.

4 REAL, Alberto Ramón. Estado de Derecho y Humanismo Personalista. F.C.U., Montevideo, 1974, p. 125.

JIMENEZ DE ARECHAGA, Justino. Teoría del Gobierno. F.C.U., Montevideo, 2016, pp. 90-91.

6 DE VERGOTTINI, Giusseppe. Derecho Constitucional Comparado. Editorial Universidad. Buenos Aires. 2005, p. 268. 
Es decir pues que los caracteres fundamentales son: el sometimiento del Estado al Derecho; la consagración de los derechos individuales y su efectiva garantía y la existencia de un sistema de control apropiado y efectivo.

\subsubsection{El Estado Social de Derecho.}

A principios del siglo XX se inicia la transformación, del Estado Liberal de Derecho, apareciendo los llamados derechos de la segunda generación o económicos, sociales o culturales y revisándose entre otros, el concepto tradicional de igualdad.

Debe recordarse que en la historia constitucional, esta etapa está signada por la Constitución de Querétaro de 1917, la Constitución de Weimar de 1919, y la Constitución española de 1931. Los cambios fueron profundos ya que si bien tanto los derechos sociales como los individuales aparecen y se basan en una exigencia humana, los derechos individuales tienen su raíz en un ser abstracto mientras que los sociales son derechos del hombre "situado" y condicionado por el ambiente en que vive. Si bien la igualdad, junto con la libertad, siguen siendo el punto de partida de la concepción, como premisa básica e inherente al hombre, se reconoce que en los hechos dicha libertad y dicha igualdad no siempre existe, por lo que esta libertad e igualdad se transforman en objetivos a alcanzar, sin perjuicio de su valor abstracto como punto de partida.

Fue la Constitución alemana de 1949, llamada originalmente la Ley Fundamental de Bonn, que establece en el art. 20 parágrafo 1 que "La República Federal de Alemania es un Estado federal, democrático y social”, el artículo 1 de la Constitución española de 1978, en la Constitución de Colombia de 1991 y en la Constitución del Paraguay de 1992, la Constitución de la Federación Rusa de 1993.

La Constitución italiana de 1946 recoge en el inciso primero de su art. $3^{\circ}$, el concepto de igualdad formal tradicional, pero complementado. "Todos los ciudadanos son iguales en dignidad social y son iguales ante la Ley, sin distinciones de sexo, de raza, de lengua, de religión, de opinión política, de condición personal o social". Pero agrega "Es competencia de la República remover los obstáculos de orden económico y social, que, limitando de hecho la libertad y la igualdad de los ciudadanos, impidan el pleno desenvolvimiento de la persona humana y la efectiva participación de todos los trabajadores en la organización política, económica y social del país".

El Estado social de Derecho reconoce una nueva realidad en la cual se advierte que no todos los hombres viven libres e iguales en derechos y, existiendo diversos obstáculos que impiden la vigencia efectiva de este concepto, el estado asume la obligación de superar los mismos, a los efectos de alcanzar dichos objetivos.

Se aprecia un cambio en cuanto al papel del Estado en materia de derechos fundamentales, ya que no basta con el que el Estado se abstenga de intervenir, sino que debe intervenir cuando sea necesario para asegurar un mínimo de vigencia real y efectiva de estos derechos fundamentales.

Buena parte de la problemática del Estado Social de Derecho radica en determinar cuáles son los límites, máximos y mínimos que debe presentar el intervencionismo estatal. Estas Constituciones van a mantener lo derechos de la primera generación, y por tanto el intervencionismo no puede reducir a cero los derechos. Va a haber un intervencionismo máximo y mínimo, dentro del cual el Estado debe actuar. 
Se señala que el Estado social de Derecho tuvo un origen híbrido, fruto del compromiso entre tendencias ideológicas dispares: por un lado, significó una conquista política del socialismo democrático; por otro lado, es fruto del pensamiento liberal más progresista.

Con acierto señala ALVAREZ CONDE, al referirse a la problemática del Estado Social de Derecho, expresión que fuera acuñada por Herman HELLER en 1929, que en la misma confluyen dos corrientes doctrinales: "por un lado, la crítica socialista al Estado liberal; $y$, por otro, con los propios planteamientos del Estado capitalista, donde hay que distinguir entre las reacciones totalitarias del mismo, cuya máxima expresión viene representada por el auge de los fascismos en el período de entreguerras, y los que pudiéramos llamar planteamientos reformistas, que son los que darán lugar a la acuñación del Estado social de Derecho"7.

Señala DE VERGOTTINI, que el "Estado social de derecho modifica los aspectos individualistas mediante una orientación intervencionista que implica el recurso a la programación económica e introduce la tutela de los intereses individuales en el cuadro de los intereses colectivos"8.

\subsubsection{El Estado social y democrático de Derecho.}

La Constitución española de 1978 no se limitó a consagrar el concepto de HELLER del Estado Social de Derecho, sino que utilizó la forma Estado Social y Democrático de Derecho.

ALVAREZ CONDE ha estudiado este artículo primero y ha señalado en primer lugar que se trata de un estadio al que la Constitución española aspira a llegar, pero que el término democrático refiere a la existencia de presupuestos de existencia del Estado democrático en el que señala la proclamación de la soberanía popular, la aceptación del pluralismo político y social y el reconocimiento de la participación de los ciudadanos, en sus diversas manifestaciones ${ }^{9}$.

Por su parte HARO, señala que la concepción moderna del Estado de Derecho conjuga las tres facetas: la social, la jurídica y la democrática, citando a GARCÍA PELAYO al analizar la Constitución española "en la situación histórica presente, ninguno de estos términos puede afirmarse sin interacción de los otros, porque ni es sólo Estado de Derecho, ni sólo Estado social, ni sólo democracia, sino que cada uno de esos enunciados condiciona y nutre a los demás"10.

El tercero de los JIMÉNEZ DE ARÉCHAGA, refiriéndose a las características básicas de un régimen democrático, señalaba que no puede confundirse esta forma de gobierno con otras autoritarias, aunque éstas hayan adoptado la expresión democracia ya sea en sentido falso o a veces totalmente diverso a la acepción normal de la palabra.

Señalaba que: 1). El régimen democrático representativo es un régimen para hombres libres. 2). Fundado en la igualdad de derechos de todos los individuos. 3). La fuente de todo

7 ALVAREZ CONDE, Enrique. Curso de Derecho Constitucional, Tomo I, Segunda Edición, Editorial TECNOS, Madrid, 1996, p. 111.

8 DE VERGOTTINI, Giusseppe. Ob. Cit., p. 251.

9 Ver: ALVAREZ CONDE, Enrique. Ob. Cit., pp. 113-130.

${ }^{10}$ HARO, Ricardo. "Algunas reflexiones sobre el Estado social y democrático de Derecho", en Revista de Derecho de la Universidad Católica del Uruguay N 7, AMF-Konrad Adenauer, 2005, p. 222. 
poder está en el pueblo. 4). Distribución de poderes entre diversos centro de autoridad que se equilibran recíprocamente. 5). Los gobernantes son responsables por todos sus actos. 6). Es un Estado de Derecho. 7). Implica un régimen de Justicia Social. Por tanto se advierte la unión en forma clara e inseparable de la noción de Estado democrático con la de Estado Social de Derecho.

En la actualidad el concepto de Estado social y democrático aparece como una unidad, al decir de RISSO, en la medida que ninguno de los componentes puede subsistir sin desnaturalizarse en forma conjunta de los restantes, tal como señalara HARO al citar a GARCÍA PELAYO.

\subsubsection{El Estado Constitucional de Derecho.}

Actualmente se habla de dos concepciones de Estado de Derecho, el Estado legalista y el Estado Constitucional, caracterizado este último por la primacía de la Constitución por encima de la primacía de la ley, la aplicación directa de las normas constitucionales y el control de constitucionalidad de las leyes. El Estado constitucional supone además la plena consagración de los derechos humanos de la tercera generación, conocida como derechos culturales, tales como el derecho a la paz, etc.

En el Estado constitucional, la Constitución es la que determina el contenido de la Ley, el acceso y el ejercicio de la autoridad y la estructura del poder. Como señala AVILA SANTAMARÍA "la Constitución es material, orgánica y procedimental. Material porque tiene derechos que serán protegidos con particular importancia, que a su vez, serán el fin del estado; orgánica porque determina los órganos que forman parte del estado y que son los llamados a garantizar derechos; procedimental porque se establecen mecanismos de participación que procuran que los debates públicos sean informados y reglados, tanto para la toma de decisiones como para la elaboración de normas jurídicas"11.

En la actualidad, autores como FERRAJOLI, han señalado la crisis actual de ambos modelos de Estado de Derecho. La situación económica y social del mundo actual, los problemas vinculados a la migración y al costo económico de los derechos consagrados, resultado que se ve en la reciente reforma constitucional española que estableció que el gasto social se dará en relación a la existencia de fondos que permitan cubrir los gastos.

\subsection{Los institutos de gobierno directo.}

\subsubsection{Democracia directa y democracia representativa.}

Uno de los criterios para la clasificación de los sistemas de gobierno, es el que toma en cuenta las relaciones entre el pueblo o la ciudadanía y el gobierno, en donde se distingue el gobierno directo, el gobierno representativo y el gobierno semi-representativo o semidirecto.

El gobierno directo puede ser definido como una forma de gobierno en la cual el pueblo participa de manera continua en el ejercicio directo del poder. Se trata de una democracia

${ }_{11}$ AVILA SANTAMARÍA, Ramiro. "Del Estado legal de derecho al Estado constitucional de derechos y justicia”, en Anuario de Derecho Constitucional Latinoamericano $\mathrm{N}^{\circ} 15$, Fundación Konrad Adenauer, 2005 , p. 778. 
auto-gobernante. El pueblo reunido en asamblea, delibera y decide en torno a los asuntos públicos.

El gobierno representativo, puede ser definido como una "democracia indirecta, en la que el pueblo no gobierna pero elige representantes que lo gobiernan". Este es el sistema que sustituye al gobierno directo, dada la imposibilidad de que el pueblo por sí mismo ejerza las funciones jurídicas del Estado.

El gobierno semi-representativo o semi-directo supone la introducción de instrumentos propios del gobierno directo en el gobierno representativo. Se trata de un gobierno representativo que tiene institutos de gobierno directo, de manera tal que la ciudadanía pueda incidir directamente en los asuntos de gobierno, tomando postura en algunos casos, e incluso decidiendo discrepancias con las autoridades que han sido elegidos por ellos.

\subsubsection{Institutos de gobierno directo.}

Siguiendo a GONZALEZ RISSOTO estamos ante institutos de gobierno directo "cuando los miembros de una sociedad que están habilitados para sufragar, toman parte activa y directa, sin intermediarios, del proceso de toma de decisiones políticas sobre el ordenamiento constitucional o legal vigente"12.

En el Derecho comparado, existen tres institutos de gobierno directo: consulta popular, iniciativa legislativa popular y la revocatoria de mandato.

La consulta popular, plebiscito o referéndum, son términos que se utilizan indistintamente en los diferentes países, y constituye el más utilizado de los mecanismos de democracia directa. La consulta popular puede ser obligatoria o facultativa. La obligatoria puede ser a). automática, cuando se está frente a un caso previsto en la Constitución, (El Salvador, Panamá y Guatemala) y b). obligatoria acotada a determinados procedimientos, que sólo son iniciados cuando surge una situación predefinida (Perú y Chile).

Las consultas facultativas pueden ser dividas en dos grupos: a) cuando la iniciativa proviene desde arriba (cuando son los órganos estatales los que tienen de manera exclusiva el derecho de poner en marcha el mecanismo), y b) cuando la iniciativa viene desde abajo, es decir de la propia ciudadanía.

Por su carácter, los resultados de las consultas populares pueden ser vinculantes o no, y en caso de ser vinculantes con o sin exigencia de un determinado quórum.

El segundo mecanismo de democracia directa es la iniciativa popular, entendiendo por tal el derecho de la ciudadanía de proponer proyectos de ley y reformas legales o constitucionales, totales o parciales. Se trata de iniciativas populares ad-parlamentum, ya que los proyectos de ley o reforma constitucional presentados son estudiados por el parlamento y la decisión al respecto la toma éste sin consultar con el electorado.

Hay unos pocos países que cuentan con una auténtica actividad legislativa de origen popular, entre los que se encuentra Uruguay.

12 GONZALEZ RISSOTO, Rodolfo. "La democracia directa en Uruguay", Revista de Derecho Electoral de Costa Rica $\mathrm{N}^{\circ}$ 6, Segundo Semestre, 2008, p. 3.

Disponible en: http://www.tse.go.cr/revista/art/6/GONZALEZ.pdf Fecha de consulta: 10.03.2019. 
La revocatoria de mandato consiste en la facultad de dejar sin efecto el mandato del titular de un cargo de elección popular. Esta posibilidad queda limitada al ámbito subnacional a excepción de Colombia, Ecuador, Panamá y Venezuela que sí lo contemplan a nivel nacional. Y en el caso de Venezuela está establecido para todos los cargos electivos, incluido el de Presidente de la República.

\section{LOS DECRETOS DE LOS GOBIERNOS DEPARTAMENTALES CON FUERZA DE LEY EN SU JURISDICCIÓN.}

\subsection{Razones de su Denominación.}

Se les llama decretos porque asílos denomina el constituyente, reiteradamente, en los artículos 273 numeral $1^{\circ}, 275$ numerales $2^{\circ}$ y $6^{\circ}, 277,281,299,300$ y 303 . De ello se deriva que son leyes materiales o actos-regla, esto es actos que poseen la nota de la generalidad y crean normas objetivas e impersonales.

Su denominación permite concluir que no son leyes formales, actos sancionados por los órganos del Poder Legislativo y promulgados por el Poder Ejecutivo.

Se les califica de legislativos porque el artículo 273 principia diciendo que "La Junta Departamental ejercerá las funciones legislativas y de contralor en el Gobierno Departamental" y porque además, el artículo 260 dispone: "Los decretos de los Gobiernos Departamentales que tengan fuerza de ley en su jurisdicción, podrán también ser declarados inconstitucionales, con sujeción a lo establecido en los artículos anteriores".

Se agrega que estos decretos legislativos son de los "Gobiernos Departamentales" porque deben ser promulgados por el Intendente Municipal, requisito sin el cual no pueden entrar en vigencia.

\subsection{El Procedimiento Legislativo Departamental.}

Tres aspectos regula la Constitución respecto a este procedimiento: el poder de proposición, la promulgación y la publicación de estos decretos.

\subsubsection{El poder de proposición.}

Tienen iniciativa en materia de decretos los Intendentes y los miembros de las Juntas Departamentales. Sobre estos últimos AGUIRRE señala que si bien la facultad de iniciativa no surge del texto constitucional, se entiende que al pertenecer a un órgano pluripersonal es una facultad inherente la "de proponer en su seno el dictado o sanción de aquellos actos que forman parte de su competencia"13.

\subsubsection{La promulgación.}

Los decretos legislativos de los Gobiernos Departamentales son actos complejos, que no se perfeccionan sin las voluntades de la Junta Departamental, que los sanciona, y del Intendente Municipal, que debe promulgarlas para que puedan entrar en vigencia u observar aquéllos que crea inconvenientes.

${ }_{13}$ AGUIRRE RAMÍREZ, Gonzalo. Derecho Legislativo: teoría general de la Ley, Edit. F.C.U., Montevideo, 1997, p. 136. 
De esta disposición resulta que el Intendente puede adoptar tres decisiones, al serle comunicados la sanción de un decreto legislativo: promulgarlo, "dentro de los diez días de recibidos", observarlo, oponiéndose a su entrada en vigencia, o guardar silencio durante los diez días siguientes al de la recepción de la comunicación de la Junta, en cuyo caso "se considerarán promulgados y se cumplirán como tales".

La promulgación no significa que el decreto entre en vigencia de inmediato, la vigencia depende de lo que diga el propio decreto acerca de la fecha en que sus disposiciones comenzarán a aplicarse, que bien puede ser, la del $1^{\circ}$ de enero del año siguiente.

El Intendente deberá formular ese tipo de observaciones para no incumplir, él, el artículo 275, numeral $1^{\circ}$ de la Constitución, que le obliga a "cumplir y hacer cumplir la Constitución y las leyes". La Junta Departamental podrá levantar las observaciones por un pronunciamiento de los tres quintos del total de componentes o sea que precisan diecinueve de los treinta y un integrantes del Cuerpo, la Constitución no ha fijado plazo al mismo.

\subsubsection{La publicación ${ }^{14}$.}

Pero además, a la promulgación debe seguir la publicación que es obligatoria a tenor del artículo 275, pues la atribución de "Promulgar y publicar los decretos sancionados por la Junta Departamental".

La publicación es potestad y obligación del Intendente, es “conditio sine qua non" de la entrada en vigencia de los decretos legislativos sancionados por la Junta Departamental.

\subsection{Determinación de la materia legislativa departamental.}

Se requiere acto legislativo departamental o decreto con fuerza de ley en su jurisdicción, para: a)- Sancionar los presupuestos departamentales (artículo 273 , numeral $1^{\circ}$, artículo 275, numeral $3^{\circ}$ ). b)- Crear o modificar impuestos, tasas y contribuciones (art. 273, numeral 3, art. 275 numeral $4^{\circ}$ y 297). c)- Fijar precios por la utilización o aprovechamiento de los bienes o servicios departamentales (art. 273, numeral 3, art. 275 numeral $4^{\circ}$ y 297). d)- Crear nuevas Juntas Locales. e)- Sancionar el Estatuto de sus funcionarios. f)Sancionar, en ejercicio de sus poderes de policía, ordenanzas de tránsito, de espectáculos públicos, de vialidad pública, de policía higiénica y sanitaria de las poblaciones y, en general, en toda materia de su competencia.

\subsection{VALOR Y FUERZA DE LOS DECRETOS DE LOS GOBIERNOS DEPARTAMENTALES ${ }^{15}$.}

Este criterio expuesto en la doctrina uruguaya por CASINELLIMUÑOZ, establece que la fuerza de un acto jurídico es la aptitud que tiene para derogar o modificar lo que disponen

14 Sobre el particular, puede verse: BORCHE ALONSO, Alejandro. "La publicación de los Decretos de los Gobiernos Departamentales con fuerza de Ley en su jurisdicción”, en Revista de Derecho Público $\mathrm{N}^{\circ} 45,2014$. Edit. FCU, pp. 37-55.

15 Puede verse: VAZQUEZ, Cristina. "Algunas reflexiones acerca de los criterios aplicables a la solución de antinomias entre Ley nacional y acto legislativo departamental", Anuario de Derecho Administrativo, Tomo VIII, Edit. F.C.U., 1990, pp. 231-238. 
otros actos de igual o distinta naturaleza. El valor de un acto jurídico está dado por la posibilidad de dejar de aplicarse.

Estos decretos tienen "fuerza de ley en su jurisdicción", lo que significa que el ámbito de aplicación es la del Departamento en que ejercen sus funciones la Junta Departamental sancionadora de dichos decretos y el Intendente que los promulga. Fuera del territorio del respectivo departamento, tales decretos carecen de toda validez.

En primer lugar, los mismos decretos derogan a los decretos anteriores, sancionados por la Junta Departamental sobre la misma materia, en tanto sus preceptos sean incompatibles.

En segundo lugar, estos decretos derogan a los actos administrativos del Intendente, toda vez que sus preceptos colidan con dichos actos, sean actos-regla, actos subjetivos o actos condición. Lo propio cabe expresar respecto de los actos de las Juntas Locales, que por regla general están en relación de dependencia con el Intendente, pero que también puede la ley haberles conferido autonomía, quebrando ese vínculo con el titular de la Intendencia.

En tercer lugar, la Constitución posterior los deroga si contienen preceptos irreconciliables con su contenido dispositivo. También derogan los decretos posteriores del mismo Gobierno Departamental, toda vez que dispongan sobre la misma materia.

En cuarto lugar, pueden ser declarados inconstitucionales por la Suprema Corte de Justicia, por razón de forma o de contenido, del mismo modo que las leyes ordinarias.

\section{LA INICIATIVA Y EL REFERENDUM DEPARTAMENTAL.}

\subsection{Iniciativa departamental.}

La Constitución uruguaya establece en el inciso segundo del artículo 304 que "También podrá la ley, por mayoría absoluta de votos del total de componentes de cada Cámara, instituir y reglamentar la iniciativa popular en materia de Gobierno Departamental".

Esta disposición tiene su fuente en la Constitución de 1952, y fue inalterada en la Constitución de 1967, vigente con las modificaciones posteriores.

Bajo la Constitución de 1934 se creó el instituto en materia local y se crea por Ley el derecho de iniciativa departamental. En efecto, la Ley N 9.515 de 24 de octubre de 1935, conocida como Ley Orgánica Municipal, establece en su artículo 79, que el quince por ciento de los inscriptos residentes en un Departamento tienen el derecho de iniciativa ante las Juntas Departamentales.

JIMÉNEZ DE ARÉCHAGA sostuvo que bajo la vigencia de la Constitución de 1942 (texto igual que el de 1934), no era posible ampliar por ley el derecho de iniciativa a la materia departamental, entendiendo que "se encomendó al Cuerpo Electoral la realización de ciertos actos de soberanía, pero en representación del soberano. El Cuerpo Electoral actúa en esos casos con todas las limitaciones que actúan los otros cuerpos representativos. Limitaciones de oportunidad, porque el pueblo no puede votar en cualquier momento, no se pueden presentar iniciativas en cualquier circunstancia; no se puede reclamar el referéndum en cualquier instante. Limitaciones de competencia, porque el Cuerpo Electoral no puede sino votar, o iniciar reformas constitucionales o intervenir en referéndum. Limitaciones de forma, porque la Constitución previene cómo se vota, cómo 
se propone la iniciativa de reforma constitucional y cómo se interviene en el referéndum. $Y$ limitaciones fin, que derivan de la teoría general de la Constitución". ${ }^{16}$ Concluye el Maestro señalando que en materia de iniciativa legislativa a nivel departamental solo tienen competencia el Intendente y los miembros de la Junta Departamental.

La Constitución de 1952 estableció el texto actual, y por tanto se entendió que el artículo 79 de la Ley $N^{\circ} 9.515$ no contradice el texto de la Carta Magna, ya que estableció que la Ley debía crear este instituto.

Entendemos que el artículo 79 de la Ley $N^{\circ} 9.515$ se encuentra vigente, por aplicación del artículo 329 de la Constitución uruguaya vigente.

\subsection{Referendum departamental.}

La Constitución uruguaya establece en el inciso primero del artículo 304 que "La ley, por mayoría absoluta de votos del total de componentes de cada Cámara, reglamentará el referéndum como recurso contra los decretos de las Juntas Departamentales".

Las multicitada Ley Orgánica Municipal, estableció que el recurso de referéndum podrá entablarse por un quinto de los ciudadanos inscriptos del Departamento para que se deje sin efecto un decreto o resolución de la Junta Departamental.

La declaración de que se quiere emplear este recurso deberá presentarse al Intendente dentro de los cuarenta días siguientes a la publicación del decreto o resolución de que se trata.

Quedarán suspendidos los efectos del acto del cual se recurre al referéndum, hasta que se produzca éste, desde el momento en que el Intendente reciba la declaración a que se refiere el artículo anterior.

El referéndum deberá efectuarse pasados los treinta días y dentro de los sesenta siguientes a la fecha en que les sean presentadas al Intendente las peticiones populares. Corresponderá al Intendente, por medio de la Junta Electoral, disponer todo lo necesario para que el referéndum se efectúe.

Los recurrentes al referéndum podrán solicitar que éste se realice en la más próxima elección, caso en el cual el pedido de referéndum no tendrá efecto suspensivo.

En el referéndum la votación se hará por sí o por no, y su resultado se publicará y tendrá fuerza ejecutoria de inmediato.

\section{3. jurisprudencia de la Corte Electoral.}

La jurisprudencia de la Corte Electoral puede dividirse en tres momentos. Un primer momento que podemos denominar de inexistencia de ambos institutos, un segundo momento que consagra su existencia, y un tercer momento que establece la vigencia del recurso de referéndum pero limita su ejercicio.

16 JIMÉNEZ DE ARÉCHAGA, Justino. La Constitucional Nacional, Tomo III, Edición Cámara de Senadores, 1998, p. 5. 


\subsubsection{Inexistencia de ambos institutos para la Corte Electoral.}

La jurisprudencia de la Corte Electoral en materia de iniciativa y referéndum departamental, hasta los años 2013 y 2014 puede calificarse de inexistencia.

En efecto, múltiples sentencias con diversas integraciones, establecieron que bajo la vigencia de la Constitución de 1934 se crearon la iniciativa y el referéndum departamental en la Ley N 9.515, de 28 de octubre de 1935 (denominada “Ley Orgánica Municipal"). En el artículo 7474 instituyó el recurso de referéndum el que "podrá entablarse por un quinto de los ciudadanos inscriptos en el Departamento para que se deje sin efecto un decreto o resolución de la Junta Departamental". Y en al artículo 79 de la misma ley instituyó el derecho de iniciativa ante la Junta Departamental que podría ser ejercido por el $15 \%$ de los inscriptos en el departamento. Y para el caso de negativa tanto expresa como ficta de la respectiva Junta Departamental quedaba expedita la convocatoria a referéndum.

A partir de la reforma constitucional de 1952 (los artículos 304 y 305 de la actual Constitución mantienen los mismos números e idéntico contenido que los de la citada reforma) se entendió en diversos fallos dictados por la Corte Electoral que era necesario que la ley reglamentaria fuera una ley posterior y no una ley preexistente a las normas constitucionales de referencia. En otras palabas, la posición histórica de la Corte Electoral, con diversas integraciones, fue que la iniciativa popular y el referéndum departamental reglamentaos por la Ley $\mathrm{N}^{\circ} 9.515$ habían quedado derogados por el texto constitucional de 1952.

\subsubsection{El cambio de la jurisprudencia: la existencia de los institutos.}

El segundo momento, en el que calificamos como existencia de la iniciativa y del referéndum, se dio con las Sentencias N²7.193 y N²7.198. Compartimos los fundamentos de ambas sentencias, que asientan un cambio en la jurisprudencia de la Corte Electoral, al interpretar correctamente la Constitución uruguaya y la normativa establecida en la Ley.

La Corte Electoral entendió que correspondía proceder al análisis de la pertinencia o no de los institutos en cada una de las sentencias señalas.

En primer lugar, sostuvo que "el tiempo verbal empleado por la norma constitucional es irrelevante". En segundo lugar, "juridicamente es admisible que preceptos anteriores al texto constitucional lo reglamenten (en el caso los articulos 74 a 79 de la Ley $N^{\circ}$ 9.515) manteniendo aquellas su fuerza y vigor por aplicación del artículo 329 de la Carta ('Decláranse en su fuerza y vigor las leyes que hasta aqui han regido en todas las materias y puntos que directa o indirectamente no se opongan a esta Constitución ni a la las leyes que expida el Poder Legislativo')". Citando a Risso señaló que "la sanción de una disposición constitucional no puede afectar la vigencia de una ley anterior, salvo que haya oposición o disposición expresa que imponga la derogación"17. En tercer lugar señaló que "el método de interpretación de las disposiciones constitucionales y legales y su vinculación con el resto del ordenamiento jurídico debe agotar el análisis textual y de interrelación de sus normas concebidas como una unidad sistemática. Los antecedentes como

${ }_{17}$ RISSO FERRAND, Martín. Derecho Constitucional, Segunda Edición, F.C.U., 2006, p. 164. 
de los que se ha valido la Corporación en los fallos relacionados anteriormente, y en otros no citados (historia de la sanción del proyecto constitucional de 1951 en lo que respecta a la disposición que a la sazón diera lugar al actual artículo 304 de la Constitución de la República) deben ser tomados en cuenta-únicamente-cuando ese análisis no es suficiente para resolver la cuestión, que no es el caso en examen".

"La iniciativa departamental y el referéndum como recurso contra los decretos de las Juntas Departamentales están establecidos por la Carta. La función de la ley en la especie es meramente la de implementar las normas constitucionales sobre el punto y en el supuesto de no existir, su ausencia debería suplirse recurriendo a los medios supletorios de conformidad con lo dispuesto por el artículo 332 de la Constitución de la República (es decir, apelando "a los fundamentos de leyes análogas, a los principios generales de derecho y a las doctrinas generalmente admitidas). Por lo demás, mientras no se modifique o derogue la ley, ésta conserva toda su fuerza y vigor en todo aquello que no se oponga directa ni indirectamente al texto constitucional por aplicación de lo dispuesto por el nombrado artículo 329 de la 'lex fundamentalis'”.

En el caso particular sobre el referéndum, la Corte Electoral luego de señalar la vigencia plena del recurso contra los decretos de las Juntas Departamentales con fuerza de ley en su jurisdicción, procedió al análisis de la interposición del recurso contra la Resolución del Intendente, que se pretendió aplicar el procedimiento. Sobre dicho tópico dijo que "es el caso consignar que el objeto del recurso de referéndum en la especie, es claramente una resolución y no un decreto. Yellos no pueden ni deben confundirse. En efecto, los decretos son los actos legislativos a nivel departamental que tienen fuerza de ley en su jurisdicción según lo establece el artículo 260 de la Constitución de la República, esto es, son actos regla a nivel departamental". Y culminó señalando que "las resoluciones son actos administrativos de carácter particular y concreto (v. gr. la determinación del flechado de una calle como en el caso en análisis) a diferencia de los decretos que son generales y abstractos" 18 .

Entendemos que la posición adoptada por la Corte Electoral en los fallos señalados, es la que corresponde, conforme a un Estado Constitucional de Derecho. La limitación del ejercicio de mecanismos de participación directa de la ciudadanía, por razones interpretativas, es ilegítima. La jurisprudencia de la Corte Electoral anterior a las sentencias analizadas, vulneraron durante mucho tiempo, el derecho de las personas a poder interponer iniciativas y referéndum a nivel departamental. La Constitución uruguaya en su artículo 332 establece un mecanismo mediante el cual los preceptos de la Constitución que establezcan derechos a los individuos, como en este caso, no podrán dejar de aplicarse a falta de reglamentación respectiva. La correcta interpretación de la Corte Electoral a partir de las Sentencias $\mathrm{N}^{\circ} 27.193$ y $\mathrm{N}^{\circ} 27.198$, cumplen con el artículo 332 de la Constitución en el sentido señalado.

\subsubsection{Restricciones al recurso de referéndum por la Corte Electoral.}

En el año 2017, la Corte Electoral recibió un recurso de referéndum contra el Decreto Nº34/2016 del Gobierno Departamental de Colonia que creo el Impuesto de Alumbrado Público. Por tanto la Corporación procedió, luego del cotejo de las firmas presentadas y a

18 CORREA FREITAS, Ruben. Estudios de Derecho Público, Magró, 2013, p. 362. 
la recepción de los antecedentes por parte del Intendente de Colonia, al análisis del caso planteado.

La Sentencia N²7.333 de 22 de marzo de 2017, se refirió a dos aspectos, primero si el instituto del referéndum departamental estaba vigente, y de estarlo si procede contra Decretos que crean Tributos.

Respecto de la vigencia del instituto, la Corte Electoral por mayoría de sus integrantes estableció la plena vigencia de lo dispuesto en las Sentencias Nº 27.193 y 27.198, firmando José Arocena, Wilfredo Penco, Washington Salvo, Gustavo Silveira, Myriam Cartagena y Pablo Klappenbach. Discordes Arturo Silveira, Sandra Etcheverry y Alberto Brause ${ }^{19}$.

Respecto de la procedencia contra Decretos que establezcan tributos departamentales señaló que "si bien el Decreto 034/2016, desde el punto de vista orgánico, aparece como los demás decretos (ordinarios) que dicta la Junta, en puridad, no lo es. En efecto, lo expresado en el Considerando anterior, demuestra que el Constituyente distingue los decretos de las Juntas Departamentales de los actos jurídicos relacionados con la materia presupuestal que, aunque aprobados por normas que formalmente revisten la condición de decretos, se encuentran reglados en una sección especial de la Constitución, a saber: la XIV, titulada 'DE LA HACIENDA PÚBLICA'. En suma, del análisis que viene de exponerse, se concluye que de la mención que el artículo 304 de la Constitución hace a los decretos de las Juntas Departamentales, se exilian los dictados en materia hacendistica, tributaria o presupuestal (ibidem).

Asimismo, los decretos de dicho órganos en la citada materia se encuentra minuciosamente reglada: solo puede modificar los proyectos para solventar los recursos o disminuir los gastos, no pudiendo aprobar ningún proyecto que signifique déficit (artículo 225). Esto último se erige, pues, en un principio fundamental en materia presupuestal que el constituyente consagró. Y esta exigencia, de que el presupuesto sea equilibrado, que planea sobre la materia presupuestal, sea en lo nacional o en lo departamental, no podría desvirtuarse por un porcentaje de ciudadanos inscriptos en el departamento a quienes la norma de mayor jerarquía ninguna participación autoriza -a texto expreso-en el procedimiento de las leyes presupuestales (ibídem). Afirmar que la Constitución no establece límites por razón de materia sobre el particular, y que por consecuencia es pertinente admitir el instituto de democracia directa (referéndum) en el ámbito departamental aun cuando la norma tenga dicha naturaleza, no se concilia por razones de hermenéutica, con lo expuesto precedentemente.

Lo que viene de afirmarse no se debilita porque el artículo 303 de la Carta faculta al tercio de la Junta Departamental o a mil ciudadanos inscriptos en el departamento a impugnar (apelar ante la Cámara de Representantes) los decretos contrarios a la Constitución y a las leyes, dentro de los quince días de su promulgación. En efecto, repárese que aunque el decreto impugnado tenga por objeto el aumento de las rentas departamentales (por ejemplo, creando tributos) de hacerse lugar a la apelación se hubiera puesto en funcionamiento un mecanismo de democracia indirecta (representativa) ajena al Cuerpo

19 Cabe destacarse que José Arocena, Arturo Silveira y Miriam Cartagena asumieron posteriormente al dictado de las sentencias de 2013 y 2014, por lo que la Corte Electoral debió nuevamente establecer la vigencia del recurso. La ministra Sandra Etcheverry, firmante de las dos sentencias citadas, en este caso, suscribió por la inexistencia del recurso. 
Electoral y a los institutos de democracia directa. Lo expresado en el numeral anterior, no se enerva, asimismo, por la acción de inconstitucionalidad prevista en el artículo 260 del mismo cuerpo normativo. En estos casos lo que está en juego es la juridicidad y no la conveniencia de la norma impugnada. Tampoco la facultad otorgada al Poder Ejecutivo de apelar ante la Cámara de Representantes, por razones de interés general, los decretos que crean o modifican impuestos (artículo 300). Fuera de que, en este caso, la aplicabilidad a la materia tributaria está expresamente establecida y es la única que contempla la norma, resultando muy claro que el fundamento de este recurso es asegurar a los órganos del Poder Central, mecanismos de contralor que permitan evitar desbordes en materia impositiva, taxativamente delimitada para los Gobiernos Departamentales en el artículo 297 de la Constitución. Ninguno de estos recursos deja librada la percepción de los tributos a la voluntad de quien está obligado a pagarlos, es decir, los sujetos pasivos de la relación jurídico-tributaria (Sentencia N²5942 de 31 de julio de 1996, en lo pertinente).

Cabe agregar, de la misma forma, que el equilibrio a que se ha hecho referencia y por el que el Constituyente ha velado, asi como la integralidad (universalidad y unidad: el presupuesto debe comprender todos los gastos de los organismos estatales) no solo es de aplicación en relación a las arcas de los Gobiernos Departamentales, sino también, y en la especie, al del ente autónomo del dominio industrial y comercial del Estado, la Administración Nacional de Usinas y Trasmisiones Eléctricas (U.T.E.). En efecto, el tributo cuestionado, de prosperar la movilización, le privaría -indirecta u oblicuamente-a dicho ente percibir, asimismo, los dineros correspondientes a las deudas generadas por consumos de energía del alumbrado público del departamento. Por lo demás, el tributo de referencia fue creado por la Junta Departamental en cumplimiento de un mandato legal (artículo 679 de la Ley $N^{\circ}$ 19.355, de 30 de diciembre de 2016). Asimismo, de prosperar el referéndum el manifestado desequilibrio no podría revertirse fácilmente en virtud de los plazos y formalidades de leyes de naturaleza presupuestal, como la citada".

Por tanto concluyó que no procede el recurso de referéndum contra el Decreto $\mathrm{N}^{\circ} 034$ / 2016 de la Junta Departamental de Colonia que firmaron los Ministros José Arocena, Washington Salvo, Arturo Silveira, Myriam Cartagena, Pablo Klappenbach, Sandra Etcheverry y Alberto Brause.

Los Ministros Wilfredo Penco y Gustavo Silveira sostienen que no existen prohibiciones ni limitaciones que puedan inhibir la convocatoria para un pronunciamiento popular contra Decretos departamentales que establezcan tributos.

No compartimos los fundamentos expresados por la mayoría de los firmantes de la sentencia en análisis, ya que entendemos que la Constitución uruguaya no limita el ejercicio del derecho de referéndum contra decretos de los gobiernos departamentales en materia tributaria. En esta Sentencia, la mayoría de la Corte Electoral ha limitado ilegítimamente el ejercicio del derecho de referéndum departamental, ya que por vía interpretativa establece una diferencia en la naturaleza de los decretos de los Gobiernos Departamentales que la Constitución no distingue.

La Constitución, tal como lo señala RUOCCO, en posición que compartimos, ha "utilizado indistintamente los términos decreto de la Junta Departamental, decreto del Gobierno Departamental o inclusive la sola expresión decreto, como sinónimos, en su 
sentido orgánico-formal. La circunstancia que tales actos requieran en materia presupuestal, un procedimiento especial para su aprobación, sea cual fuere éste, no le quita la naturaleza de decreto con fuerza de ley en su jurisdicción, en tanto que ejercicio de función legislativa"20.

\section{CONCLUSIONES.}

En primer lugar, entendemos que en un Estado constitucional de Derecho no es posible limitar el ejercicio de la soberanía directa por parte del Cuerpo Electoral, ya que, como señala GROS ESPIELL, se trata del Cuerpo Electoral Departamental actuando en el referéndum en materia departamental contra los Decretos de las Juntas Departamentales y la iniciativa popular en materia de Gobierno Departamental. Así también profundiza la estricta aplicación del principio de legalidad en tanto la interpretación que da la Corte en lo formal fortaleciendo con esta posición la participación popular como pilar de todo gobierno democrático.

En segundo lugar, la histórica interpretación de la Corte Electoral respecto a la inexistencia de ambos recursos señalando que la Constitución de 1952 derogó lo dispuesto en la Ley 9515 de acuerdo a los fundamentos señalados, fue violatoria del artículo 332 de la actual Constitución uruguaya (que fue establecida en la Constitución de 1942), ya que allí se dan las pautas o lineamientos básicos para la interpretación de aquellas normas o preceptos constitucionales que no han sido reglamentados, pero que igualmente deben ser aplicados.

En tercer lugar, entendemos que las Sentencias No27.193 y 27.198 asientan la interpretación acertada de la Constitución uruguaya respecto de los institutos que hemos analizado, y compartimos la plena vigencia de las normas establecidas en la Ley 9.515, con las excepciones señaladas.

En cuarto lugar, no compartimos el fallo de 22 de marzo de 2017, cuando la Corte Electoral realiza una restricción que la Constitución uruguaya no establece, interpretando la existencia de decretos del gobierno departamental con diferente naturaleza a la ordinaria, cuando se trata de aquellos que refieren al presupuesto y que crean tasas, impuestos y contribuciones, señalando que son de competencia privativa del Intendente y se encuentran excluidos del recurso de referéndum.

En quinto lugar, los ministros firmantes de la Sentencia $\mathrm{N}^{\circ} 27.333$ interpretan erróneamente la Constitución uruguaya, ya que tal y como señalaba CASSINELLI " $L a$ Constitución prevé la existencia de referéndum contra los decretos departamentales pero no dice en qué caso corresponde ni qué mayoría se requiere ni ningún otro detalle sobre la reglamentación. Eso lo deja librado a la Ley Ordinaria, a diferencia de lo que ocurre en materia nacional, donde está todo reglamentado en la propia Constitución, que dice que el recurso de referéndum no puede corresponder contra las leyes que establezcan tributos o las que sean de iniciativa del Poder Ejecutivo".

20 RUOCCO, Graciela. "El referéndum contra los decretos departamentales", en El Poder y su Control, Edit. Revista Uruguaya de Derecho Constitucional y Político, Segunda Edición, 1994, p. 55. 
"En cambio, en materia departamental, ese tema está librado a la Ley. Y la ley vigente no establece ningún distingo. Todos los Decretos de las Juntas Departamentales son susceptibles del recurso de referéndum”.

Y concluye que "si el constituyente hubiera querido que la solución fuera para los dos casos iguales, hubiera dicho que en ningún caso el referéndum procede cuando se refiere a tributos" 21 .

En sexto lugar, la Corte Electoral, si bien ha establecido en su última jurisprudencia la existencia de ambos institutos, limita ilegítimamente el ejercicio de un derecho consagrado constitucionalmente estableciendo por vía interpretativa una restricción al ejercicio de la soberanía directa por parte del Cuerpo Electoral, en este caso departamental. Entendemos que el referéndum departamental puede entablarse contra Decretos de las Juntas Departamentales que crean o modifican tributos a nivel departamental, y que la Corte Electoral viola la Constitución uruguaya con su interpretación restrictiva de derechos constitucionales consagrados al soberano.

\section{BIBLIOGRAFÍA CONSULTADA.}

AGUIRRE RAMÍREZ, Gonzalo. Derecho Legislativo: teoría general de la Ley, Edit. F.C.U., Montevideo, 1997.

ALVAREZ CONDE, Enrique. Curso de Derecho Constitucional, Tomo I, Segunda Edición, Editorial TECNOS, Madrid, 1996.

AVILA SANTAMARÍA, Ramiro. "Del Estado Legal de Derecho al Estado Constitucional de Derechos y Justicia” en Anuario de Derecho Constitucional Latinoamericano ํㅜ 15 , Fundación Konrad Adenauer, Montevideo, 2009, pp. 775-793.

BORCHE ALONSO, Alejandro. "La publicación de los Decretos de los Gobiernos Departamentales con fuerza de Ley en su jurisdicción”, en Revista de Derecho Público N 45, Enero-Julio 2014. Edit. FCU, pp. 37-55.

Disponible: http://www.revistaderechopublico.com.uy/revistas/45/Borche.html

CAGNONI, José Aníbal. "Los institutos de gobierno directo en Uruguay", en Revista de Derecho Público N 9, Enero-Julio 1996. Edit. FCU, pp. 47-54.

CASSINELLI MUÑOZ, Horacio. "Dos notas prácticas sobre abrogación constitucional”, Revista de Derecho Jurisprudencia y Administración (RDJA), Tomo 65, Año 1967, N¹-12, pp. 92-101.

CASSINELLI MUÑOZ, Horacio. "Derecho Público", Tercera Edición, Edit. F.C.U., Montevideo, 2009.

CORREA FREITAS, Ruben. Derecho Constitucional Contemporáneo, Tomo I, Sexta Edición, Edit. F.C.U., Montevideo, 2019.

CORREA FREITAS, Ruben. Derecho Constitucional Contemporáneo, Tomo II, Quinta Edición, Edit. F.C.U., Montevideo, 2016.

CORREA FREITAS, Ruben. Estudios de Derecho Público, Edit. MAGRÓ, Montevideo, 2013.

DE VERGOTTINI, Giusseppe. Derecho Constitucional Comparado. Editorial Universidad. Buenos Aires, 2005.

DELPIAZZO, Carlos. Autoridades Departamentales y Municipales, Edit. A.M.F., Montevideo, 2010.

21 CASINELLI MUÑOZ, Horacio, “Consulta constitucional”, Mundo Color, Montevideo, miércoles 3 de julio de 1985, p.7 citado por ESTEVA GALICCHIO, Eduardo, “Es constitucionalmente posible el referéndum como recurso contra un decreto de una Junta Departamental que establezca tributos?", Revista Uruguaya de Derecho Constitucional y Político, Tomo II, Junio-Julio 1985, N 7 , p. 59. 
ESTEVA, Eduardo. “Es constitucionalmente posible el referéndum como recurso contra un decreto de una Junta Departamental que establezca tributos?", Revista Uruguaya de Derecho Constitucional y Político, Tomo II, Junio-Julio 1985, N 7, pp. 57-65.

FRUGONE SCHIAVONE, Héctor. "Plebiscitos, referéndum e iniciativas populares, en el ámbito territorial departamental", Revista Uruguaya de Derecho Constitucional y Político, Tomo IX, Febrero-Mayo 1993, N 53-54, pp. 353-374.

GONZALEZ RISSOTO, Rodolfo. "La democracia directa en Uruguay", Revista de Derecho Electoral de Costa Rica $\mathrm{N}^{\circ}$ 6, Segundo Semestre, 2008.

Disponible en: http://www.tse.go.cr/revista/art/6/GONZALEZ.pdf

GROS ESPIELL, Héctor. "El ejercicio directo de la soberanía según la Constitución uruguaya y la Corte Electoral", en CEDECU Serie de Ensayos N 3, INGRANUSI, 2001.

GUTIERREZ, Fulvio. Manual Jurídico sobre los Gobiernos Departamentales, Edit. F.C.U., Montevideo, 2012.

HARO, Ricardo. "Algunas reflexiones sobre el Estado social y democrático de Derecho", en Revista de Derecho de la Universidad Católica del Uruguay N 7, AMF-Konrad Adenauer, Montevideo, 2005, pp. 219-228.

JIMENEZ DE ARECHAGA, Justino. La Constitución Nacional, Tomo III, Edit. Cámara de Senadores, Montevideo, 1998.

JIMENEZ DE ARECHAGA, Justino. Teoría del Gobierno. F.C.U., Montevideo, 2016.

MARTINS, Daniel Hugo. El Gobierno y la Administración de los Departamentos, Tomo II, Edit. Autor., Montevideo, 2003.

MENDEZ, Aparicio. "Procedimientos Objetivo de Regulación Institucional. Algunas consideraciones acerca de los llamados recursos municipales de inconstitucionalidad e ilegalidad y de 'control' presupuestal", Revista de Derecho de Derecho Público y Privado, Año 1948, № 121, pp. 259-280.

REAL, Alberto. "Iniciativa popular y referéndum, en materia legislativa (Art. 79 inciso $2^{\circ}$ de la Constitución)", en Temas Jurídicos: La Constitución de 1967, Edit. F.C.U., 1968, pp. 225-229.

REAL, Alberto Ramón. "El Estado de Derecho", en Estudios Jurídicos en memoria de Eduardo J. Couture, Edit. Facultad de Derecho y Ciencias Sociales, Montevideo, 1957, pp. 587-620.

REAL, Alberto Ramón. Estado de Derecho y Humanismo Personalista. F.C.U., Montevideo, 1974.

RODRIGUEZ VILLALBA, Gustavo. La potestad tributaria de los Gobiernos Departamentales, Edit. F.C.U., Montevideo, 1999.

RUOCCO, Graciela. "El referéndum contra los decretos departamentales", en El Poder y su Control, Edit. Revista Uruguaya de Derecho Constitucional y Político, Segunda Edición, 1994, pp. 49-63.

SANCHEZ, Alvaro. "Instrumentos de control sobre los Gobiernos Departamentales (Primera Parte), Revista de Legislación Uruguaya, Año 3, N 4, Abril 2012, pp. 87-100.

SANCHEZ, Alvaro. "Instrumentos de control sobre los Gobiernos Departamentales (Segunda Parte), Revista de Legislación Uruguaya, Año 3, N 8, Agosto 2012, pp. 67-78.

SAPOLINSKI, Jaime. "Sobre iniciativa popular y referéndum en el ámbito departamental: no se puede", Revista Uruguaya de Derecho Constitucional y Político, Tomo X, Octubre-Noviembre 1993, No 57 , pp. 353-356.

VAZQUEZ, Cristina. "Algunas reflexiones acerca de los criterios aplicables a la solución de antinomias entre Ley nacional y acto legislativo departamental", Anuario de Derecho Administrativo, Tomo VIII, Edit. F.C.U., 1990, pp. 231-238.

Fecha de recepción: 28 de abril 2019.

Fecha de aceptación: 26 de mayo 2019. 